\title{
The causality between education and GDP Growth in Asian Countries
}

\author{
Mohsen Mehrara $^{1 *}$, Maysam Musai ${ }^{2}$ \\ ${ }^{1}$ Faculty of Economics, University of Tehran, Tehran, Iran \\ ${ }^{2}$ Faculty of Social Sciences, University of Tehran \\ `E-mail address: mmehrara@ut.ac.ir,mousai@ut.ac.ir
}

\section{ABSTRACT}

This paper investigates the causal relationship between countries by using panel unit root tests and panel cointegration a three-variable model is formulated with capital formation as third iable. The results show a strong causality from investment and economic growth to e ucau on in thes Atries. Yet, education does not have any significant effects on GDP and investr ent in short- and lo, g-run. It means that it is the capital formation and GDP that drives education in nentioned colntries, not vice versa. So the findings of this paper support the point of view that it is her econo hic growth that leads to higher education proxy. It seems that as the number of enroll the quality of the education declines. Moreover, the formal education systen market oriented in these countries. This may be the reason why huge educational investments n the loping countries fail to generate higher growth. By promoting practice-oriented training studens particularly in technical disciplines and matching education system to the rece. $f$ the lat $r$ market, it will help create long-term jobs and improve the country's future pro

Keywords: Panel Unit Roo ${ }^{+}$Panel Con ration; Granger Causality; Human Capital; Asian countries

\section{INTROD CTIO}

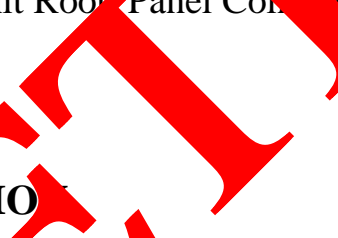

(199 are is the a a a d a d atlyation of human capital is responsible for sustained growth and eau on channel through which the human capital accumulates. Romer(1986, 1990) that numan capital, which generates innovations, stimulate growth. As it is well document the literature, education also constructs spillover affects, improves the adaptation speed of entrepreneurs to disequilibrium, and boosts research productivity.

Furthermore, there is the possibly feedback effects from economic growth to human capital. It is argued that economic growth could lead to human capital accumulation (Mincer, 1996). So, the causal chain between economic growth and education implied by the existing macroeconomic paradigms seems relatively ambiguous. The subject, therefore, as to the dynamic causal relationships in the Granger sense remains uncertain and is a practical one.

There is mixed evidence in the empirical literature regarding the relation between education and economic growth. Benhabib and Pritchett (1997) report fragile correlation 
between growth and education. Levine and Renelt (1992) show that education does not have significant impact in many of the growth regressions they have estimated. Bils and Klenow (2000) finds the weak causality from education to growth; so that the statistical significance of education in growth regressions may arise from just omitted variables. therefore, the crosssectional studies seem to yield mixed results. Dessus (1999) argues that the findings of Pritchett (1997) may be due to specification bias. Dessus' (1999) panel data results suggest that as the education quantity increase, the quality of the education decrease. This may be the reason why enormous educational investments in developing countries fail to generate higher growth.

The focus of the paper is, therefore, to examine the relationship between eacation d economic growth in 40 Asian countries for the period 1970-2010 The direct of causa between these two variables is examined by utilizing a cointegration an er correcti modeling framework. The paper is organized in four sections. Sec on 2 dis es ne methodology, data and empirical results of the study. Section 3 concly s.

\section{DATA AND EMPIRICAL RESULTS}

We apply a three variable model to examine capital GDP with gross investment included in mo lel as conditioniy variable along with these two variables. Human capital is proxied by rolment rat in all levels of education (including tertiary, secondary and primary educat measured as the percentage of the working age population) as well as public -nenditure acation relative to total public expenditures. We apply the principle com in anroach to merge the proxies into one measurement (HUM). The data were obtain d fom a Barro and Lee dataset and world development indicators. Data use the ana sis are annual time series during the period 1970-2010 on the proxy of hum in cap al, (loga 1 m of) real GDP per capita (GDP) and real investment (INV) in constap 24 a currency units for 40 Asian countries. The choice of the starting p iod was nstrained by the availability of data. The countries considered in this stu Arment Kerbaijan, Georgia, Kazakhstan, Kyrgyz Republic, Pakistan, Tajikistan, urkn istan, Uzbekistan, China People's Rep. of, Hong Kong; China, Korea Rep. of, Nongolia, Bà 'desh, Bhutan, India, Maldives, Nepal, Sri Lanka, Brunei Darussalam, ambo $q$, Indon sia, Lao PDR, Malaysia, Philippines, Singapore, Thailand, Viet Nam, 1 , Icands, Ciribati, Marshall Islands, Palau, Papua New Guinea, Samoa, Solomon-rands, nga, anuatu, Australia, Japan, New Zealand

To the no of association between the variables while avoiding any spurious testing non-stationarity in the three variables of HUM, GDP and INV. Prompted by the existence 1 it roots in the time series, we test for long run cointegrating relation between three variasles at the second step of estimation using the panel cointegration technique developed by Pedroni $(1995,1999)$. Granted the long run relationship, we explore the causal link between the variables by testing for granger causality at the final step.

\subsection{Panel Unit Roots Results}

The panel data technique referred above has appealed to the researchers because of its weak restrictions. It captures country specific effects and allows for heterogeneity in the 
direction and magnitude of the parameters across the panel. In addition, it provides a great degree of flexibility in model selection. Following the methodology used in earlier works in the literature we test for trend stationarity of the three variables of HUM, GDP and INV. With a null of non-stationary, the test is a residual based test that explores the performance of four different statistics. Together, these four statistics reflect a combination of the tests used by Levin-Lin (1993) and Im, Pesaran and Shin (1997). While the first two statistics are nonparametric rho-statistics, the last two are parametric ADF t-statistics. Sets of these four statistics have been reported in Table 1.

The first three rows report the panel unit root statistics for HUM, GDP and INU at the levels. As we can see in the table, we cannot reject the unit-root hypothesis when ne varn s are taken in levels and thus any causal inferences from the three series in le are inva The last three rows report the panel unit root statistics for first differences of $\mathrm{HL}$ GDP a INV. The large negative values for the statistics indicate rejection of the all of non tion ary at $1 \%$ level for all variables. It may, therefore be concluded that the var bles or UM, GDP and INV are unit root variables of order one, or, I (1) for shor

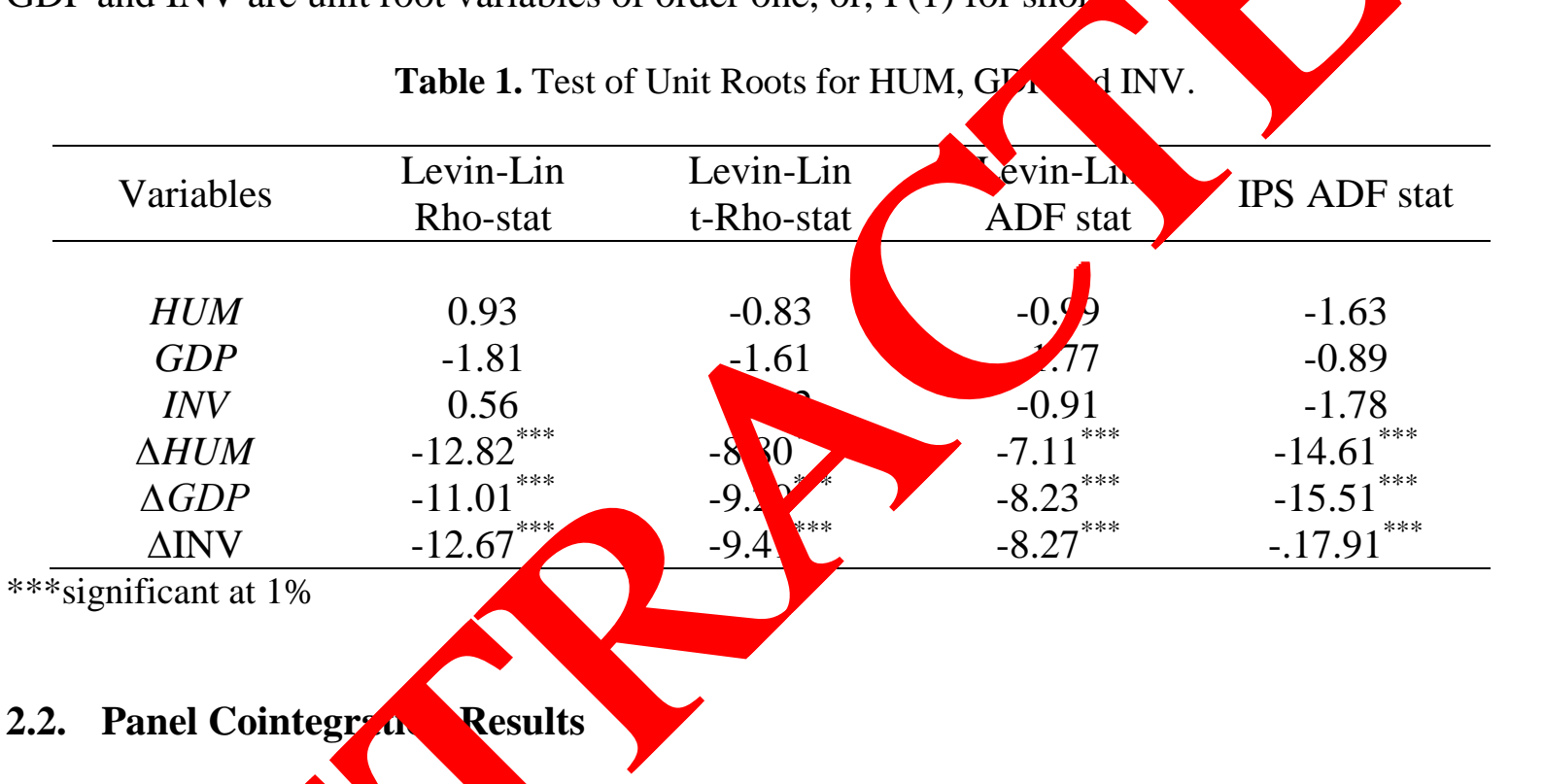

At the sec ranstep of ou timation, we look for a long run relationship among HUM, GDP and INY using the panel_cointegration technique developed by Pedroni $(1995,1999)$. This techniqu a ignifio nt improvement over conventional cointegration tests applied on a single country s. Wh pooling data to determine the common long run relationship, it alloys the integr. vectors to vary across the members of the panel. After including INV as ddit onal variaole, the cointegration relationship we estimate is specified as follows:

$$
G D P_{i t}=\alpha_{i}+\delta_{t}+\beta_{i} H U M_{i t}+\gamma_{i} I N V_{i t}+\varepsilon_{i t}
$$

Where $\alpha_{i}$ refers to country effects and $\delta_{t}$ refers to trend effects. $\varepsilon_{i t}$ is the estimated residual indicating deviations from the long run relationship. With a null of no cointegration, the panel cointegration test is essentially a test of unit roots in the estimated residuals of the panel. Pedroni (1999) refers to seven different statistics for this test. Of these seven statistics, the first four are known as panel cointegration statistics; the last three are group mean panel cointegration statistics. In the presence of a cointegrating relation, the residuals are expected to be stationary. These tests reject the null of no cointegration when they have large negative 
values except for the panel-v test which reject the null of cointegration when it has a large positive value. All of these seven statistics under different model specifications are reported in Table 2. The statistics for all different model specifications suggest rejection of the null of no cointegration for all tests except the panel and group $\rho$-tests. However, according to Perdroni (2004), $\rho$ and PP tests tend to under-reject the null in the case of small samples. We, therefore, conclude that the three unit root variables HUM, GDP and INV are cointegrated in the long run.

Table 2. Results of Panel Cointegration test.

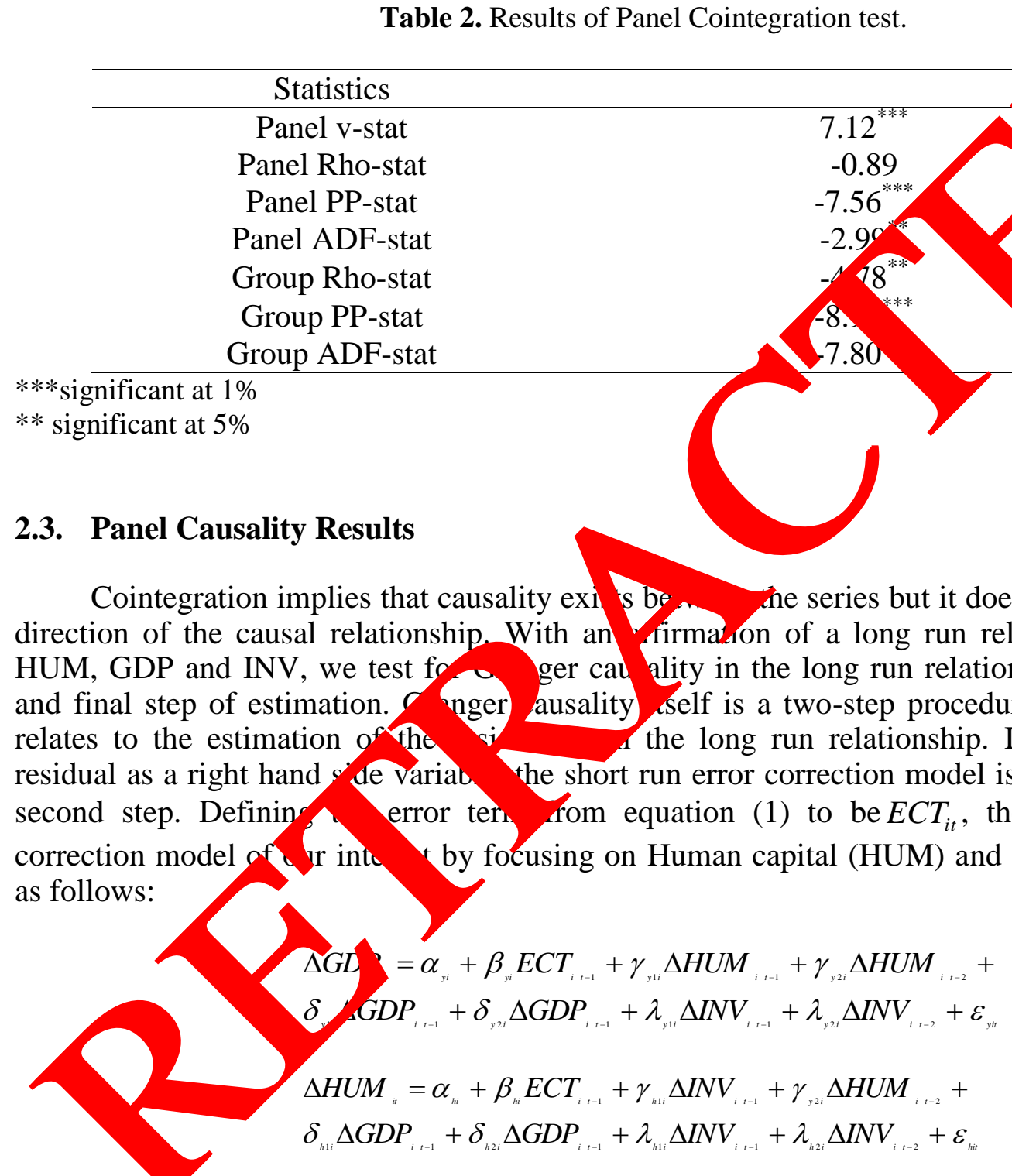

Where $\Delta$ is a difference operator; ECT is the lagged error-correction term derived from the long-run cointegrating relationship; the $\beta_{y}$ and $\beta_{h}$ are adjustment coefficients and the $\varepsilon_{y i t}$ and $\varepsilon_{h i t}$ are disturbance terms assumed to be uncorrelated with mean zero.

Sources of causation can be identified by testing for significance of the coefficients on the lagged variables in Eqs (2) and (3). First, by testing $H_{0}: \gamma_{y 1 i}=\gamma_{y 2 i}=0$ for all $\mathrm{i}$ in Eq. (2) or $H_{0}: \delta_{h 1 i}=\delta_{h 2 i}=0$ for all i in Eq. (3), we evaluate Granger weak causality. Masih and Masih (1996) and Asafu-Adjaye (2000) interpreted the weak Granger causality as 'short run' 
causality in the sense that the dependent variable responds only to short-term shocks to the stochastic environment.

Another possible source of causation is the ECT in Eqs. (2) and (3). In other words, through the ECT, an error correction model offers an alternative test of causality (or weak exogeneity of the dependent variable). The coefficients on the ECTs represent how fast deviations from the long run equilibrium are eliminated following changes in each variable. If, for example, $\beta_{y i}$ is zero, then GDP does not respond to a deviation from the long run equilibrium in the previous period. Indeed $\beta_{y i}=0$ or $\beta_{h i}=0$ for all $\mathrm{i}$ is equivalent to both the Granger non-causality in the long run and the weak exogeneity (Hatanaka, 1996).

It is also desirable to check whether the two sources of causation are join y significa in order to test Granger causality. This can be done by testing the jon hypothes $H_{0}: \beta_{y i}=0$ and $\gamma_{y 1 i}=\gamma_{y 2 i}=0$ for all i in Eq. (2) or $H_{0}: \beta_{h i}=0$ and in Eq. (3). This is referred to as a strong Granger causality test. The $i$ test dicate wich variable(s) bear the burden of short run adjustment to re-estab ${ }^{1}$ run ed iribrium, following a shock to the system (Asafu-Adjaye, 2000).

The results of the F test for both long run and short ry ality are orted in Table 3. As is apparent from the Table, the coefficients of the EC GD d INV are significant in the HUM equation which indicates that long-run and nom run caus. fun from GDP and INV to human capital. So, GDP and INV strongly ranger-causes hy nan capital. INV does Granger cause GDP at short run at 5\% level, witho any signifigant effect on output in long run. Weak exogeneity of GDP indicate that this va ble does not adjust towards long-run equilibrium.

Moreover, the interaction terms in the significant at $1 \%$ level. These results imply that, there is Granger causality Inn $1 \mathrm{G}$ GP and INV to human capital in the long-run and short run, while human cap al have a neutral effect on GDP in both the short- and long-run. In other wo as, $P$ is we kly exogenous and whenever a shock occurs in the system, human cap wou a make short-run adjustments to restore long-run equilibrium.

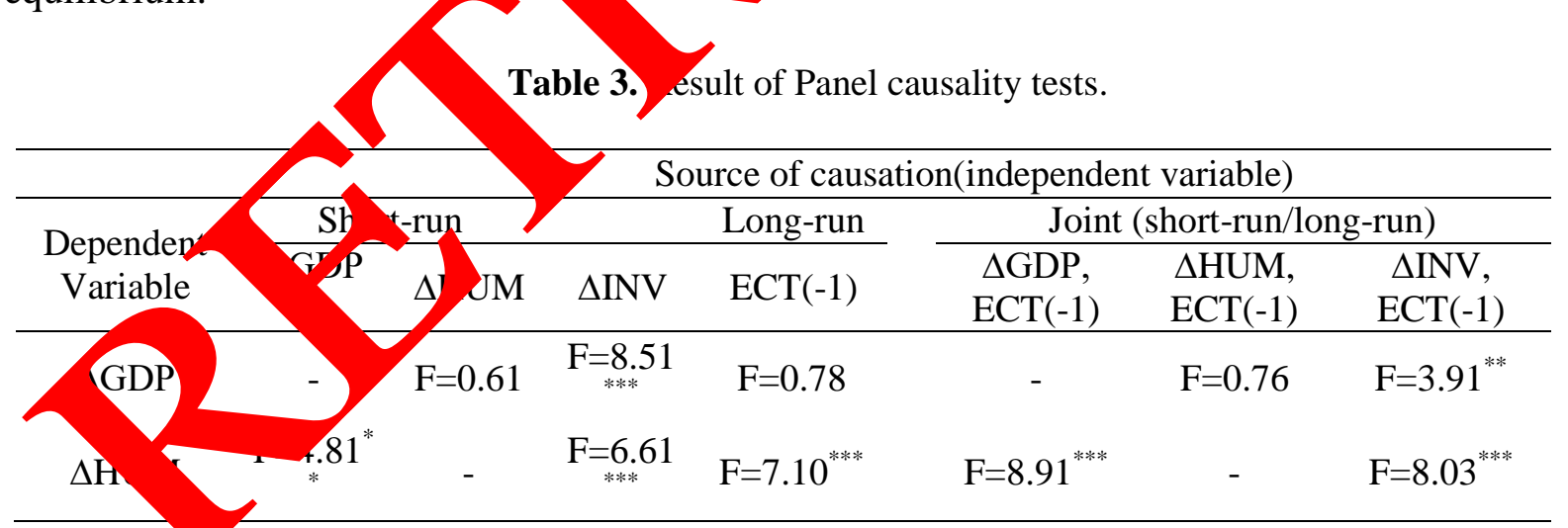

***significa $\lambda$ at $1 \%$

** significant at $5 \%$

\section{CONCLUSION}

The objective of this study is to examine Granger causality between human capital and income 40 Asian countries over the period 1970-2010. Real capital formation is also included in the model along with these two variables. The panel integration and cointegration 
techniques are employed to investigate the relationship between the three variables: human capital proxy, GDP, and investment. The empirical results indicate that we cannot find enough evidence against the null hypothesis of unit root. However, for the first difference of the variables, we rejected the null hypothesis of unit root. It means that the variables are I(1). The results show that there is a long-run relationship between human capital and GDP. Utilizing Granger Causality within the framework of a panel cointegration model, the results suggest that there is strong causality running from GDP and investment to human capital with no feedback effects from human capital to GDP for Asian countries. It means that it is the investment and GDP that drives the human capital in mentioned countries, not vice vanca. So the findings of this paper support the point of view that it is higher economic growth leads to higher human capital. According to the results, it seems that, $t$ ome exte investments have contributed to human capital and economic growth yring samp period. It seems that as the number of enrollments increase, the qua'sty of the "cat on declines. This may be the reason why huge educational investme in th dev oping countries fail to generate higher growth. In order to match educa on runitie with the demands of the labour market, support should be provided for itegrating hour narket data into educational planning and establishing technical and start a thes at un sities

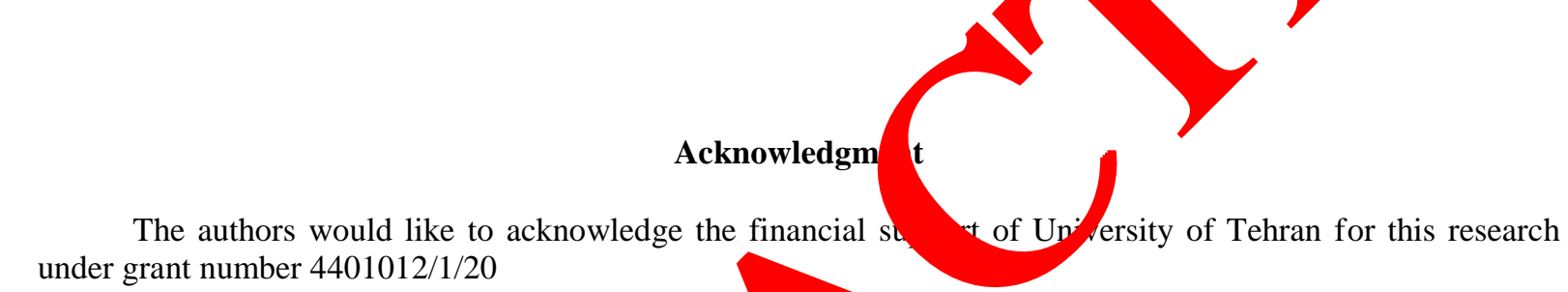
under grant number 4401012/1/20

\section{References}

[1] Aghion P., Howitt P. 19 ndo anous orowth theory, MIT Press.

[2] Alderman H., Behy an J. R., s D. R., Sabot R. 1996. The returns to endogenous human capital ir $\mathrm{Pa}$ tan's rura, age labour market, Oxford Bulletin of Economics and statistics 29-5

[3] Anderso T.W Hsiao C. 81. Estimation of dynamic models with error components. Journow the smeri an Statistical Association, 76, 598-606.

[4] A no M. ond 1991. Some tests of specification for panel data: Monte Carlo evid ce and a application to employment equations. Review of Economic Studies, 58,

[5] A noM., Bover O. 1995. Another look at the instrumental variable estimation of error omponent models, Journal of Econometrics, 68, 29-51.

[6] Barro R.J. 1991. Economic growth in a cross-section of countries, Quarterly Journal of Economics, 106, 407-443.

[7] Barro R.J. 1999. Human capital and growth in cross-country regressions, Swedish Economic policy Review, 6, 237-277.

[8] Barro R.J., Lee J.W. 1996. International measures of schooling years and schooling quality, American Economic Review, 86, 218-223. 
[9] Barro R.J., Sala-i-Martin X. 1995. Economic Growth, Mc-Graw Hill, New York.

[10] Benhabib J., Spiegel M.M. 1994. The role of human capital in economic development. Evidence from aggregate cross-country data, Journal of Monetary Economics, 34, 143173.

[11] Bils M., Klenow P. 1998. Does schooling cause growth or the other way around?" NBER Working Paper 6393.

[12] Granger, C. W. J., 1969. Investigating Causal Relations by Econometric Models and Cross-spectral Methods, Econometrica 37 (3): 424-438.

[13] Granger, C. W. J., 1988. Some Recent Developments in a Concept of Ca. ity, Journ of Econometrics 39: 199-211.

[14] Harrod, R. F., 1939. An Essay on Dynamic Theory. Economic J rnal 4 14-3

[15] Hatanaka, M., 1996. Time-Series-Based Econometrics: Uni 1 Co-int gration. Oxford University Press, Oxford.

[16] Im, K. S., Pesaran, M. H., and Shin, Y., 1997. Testipg or Un oots in Heterogeneous Panels, University of Cambridge, Department of sppmed Econo

[17] Im, K. S., Pesaran, M. H., and Shin, Y., 2003. esting for Unit Roots in Heterogeneous Panels, Journal of Econometrics 115: 53-74.

[18] Levin, A., Lin, C.F., 1992. Unit Root Asts in Pan antotic and Finite Sample Properties.Department of Econ Itmiversity of California at San Diego, Working Paper 92-23.

[19] Levin, A., Lin. C. F., 1993 om oot Tes in Panel Data: New Results. Department of Economics, University o alifo Lia, San I lego, Working paper 93-56.

[20] Levin, A., Lin, C. F, anu Ch F. S. J. 2002. Unit Root Test in Panel Data: Asymptotic and Finite Samp

[21] Masih, A.M M.,Masi 1996. Energy consumption, real income and temporal causality esults from a i 1 -country study based on cointegration and error-correction model techn yes Energy Economics 18:165-183.

[22] Pedroni, H 995,Pa Cointegration: Asymptotic and Finite Sample Properties of roo Time s Tests, with an Application to the PPP Hypothesis. Indiana Uniy rsity, Wg king Papers in Economics, No. 95-013.

[23] F Oni, P., 1997, Panel Cointegration: Asymptotic and Finite Sample Properties of Poo, Time Series Tests, with an Application to the PPP Hypothesis: New results, Indian University, Working Papers in Economics.

[24] Pedroni, P., 1999. Critical Values for Cointegration Tests in Heterogeneous Panels with Multiple Regressors. Oxford Bulletin of Economics and Statistics 61 (4): 5-49.

[25] Pedroni, P., 2004. Panel Cointegration: Asymptotic and Finite Sample Properties of Pooled Time Series Tests with an Application to the PPP Hypothesis: New Results. Econometric Theory 20 (3): 597-627. 
[26] Pesaran, M. H., Shin Y., 1997. An Autogressive Distributed Lag Modelling Approach to Cointegration Analysis, Working Paper Trinity College, Cambridge.

[27] Solow, R. M., 1956. A Contribution to the Theory of Economic Growth. Quarterly, Journal of Economics 70: 65-94.

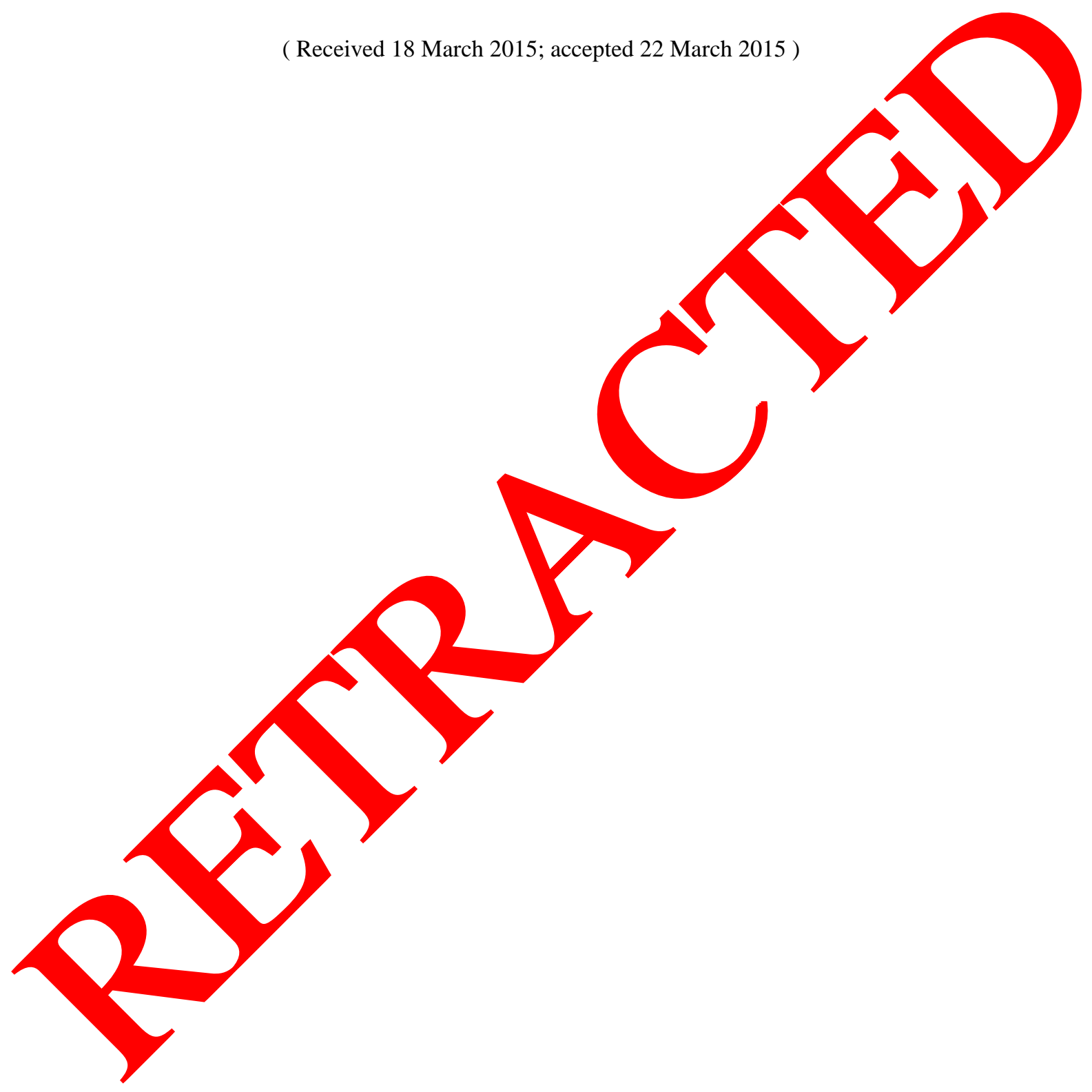

